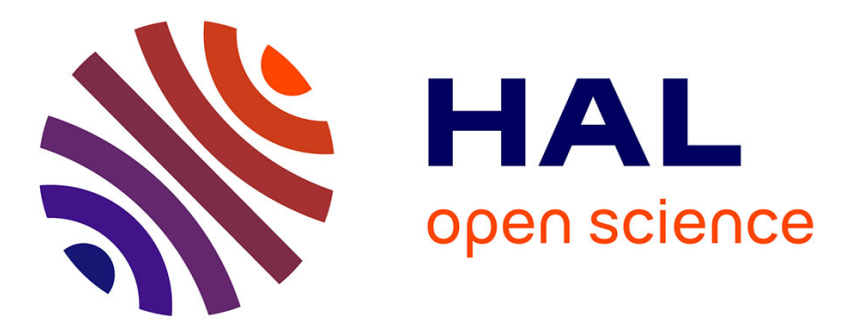

\title{
Characterization of aerosols and fibers emitted from composite materials combustion
}

C. Chivas-Joly, F. Gaie-Levrel, C. Motzkus, S. Ducourtieux, Alexandra

Delvallée, F. de Lagos, S. Le Neve, J. Gutierrez, J. -M. Lopez-Cuesta

\section{- To cite this version:}

C. Chivas-Joly, F. Gaie-Levrel, C. Motzkus, S. Ducourtieux, Alexandra Delvallée, et al.. Characterization of aerosols and fibers emitted from composite materials combustion. Journal of Hazardous Materials, 2016, 301, pp.153-162. 10.1016/j.jhazmat.2015.08.043 . hal-02906419

\section{HAL Id: hal-02906419 \\ https://hal.science/hal-02906419}

Submitted on 26 May 2021

HAL is a multi-disciplinary open access archive for the deposit and dissemination of scientific research documents, whether they are published or not. The documents may come from teaching and research institutions in France or abroad, or from public or private research centers.
L'archive ouverte pluridisciplinaire HAL, est destinée au dépôt et à la diffusion de documents scientifiques de niveau recherche, publiés ou non, émanant des établissements d'enseignement et de recherche français ou étrangers, des laboratoires publics ou privés. 


\title{
Characterization of aerosols and fibers emitted from composite materials combustion
}

\author{
C. Chivas-Joly ${ }^{\mathrm{a}, *}$, F. Gaie-Levrel ${ }^{\mathrm{b}}, \mathrm{C}$. Motzkus ${ }^{\mathrm{b}}$, S. Ducourtieux ${ }^{\mathrm{c}}$, A. Delvallée $^{\mathrm{c}}$, \\ F. De Lagos ${ }^{\mathrm{a}}$, S. Le Nevéd ${ }^{\mathrm{d}}$ J. Gutierrez ${ }^{\mathrm{e}}$, J.-M. Lopez-Cuesta ${ }^{\mathrm{f}}$ \\ a Laboratoire national de métrologie et d'essais (LNE), Pole Energie, Environnement et Combustion, 29, avenue Roger Hennequin, 78197 Trappes, France \\ ${ }^{\mathrm{b}}$ Laboratoire national de métrologie et d'essais (LNE), Département métrologie des gaz et des aérosols, 1 rue Gaston Boissier, 75724 Paris Cedex 15, France \\ ${ }^{\mathrm{c}}$ Laboratoire national de métrologie et d'essais (LNE), Plateforme CARMEN, 29, avenue Roger Hennequin, 78197 Trappes, France \\ ${ }^{d}$ DGA-Aeronautical Systems, 47 rue Saint-Jean, 31130 Balma, France \\ e DCNS Research, Indret, 44620 La Montagne, France \\ ${ }^{\mathrm{f}}$ Centre des Matériaux des Mines d'Alès (C2MA), 6 Avenue de Clavières, 30319 Alès Cedex, France
}

\section{H I G H L I G H T S}

- Aerosols emitted were characterized by particles classified as PN50.

- Particle-size mass distribution is characterized a cut-off diameter of $320 \mathrm{~nm}$.

- Nanotubes or fibers does not impact the particle mass emitted during combustion.

\section{A B S T R A C T}

This work investigates the aerosols emitted during combustion of aircraft and naval structural composite materials (epoxy resin/carbon fibers and vinyl ester/glass fibers and carbon nanotubes). Combustion tests were performed at lab-scale using a modified cone calorimeter. The aerosols emitted have been characterized using various metrological devices devoted to the analysis of aerosols. The influence of the nature of polymer matrices, the incorporation of fibers and carbon nanotubes as well as glass reinforcements on the number concentration and the size distribution of airborne particles produced, was studied in the $5 \mathrm{~nm}-10 \mu \mathrm{m}$ range. Incorporation of carbon fibers into epoxy resin significantly reduced the total particle number concentration. In addition, the interlaced orientation of carbon fibers limited the particles production compared to the composites with unidirectional one.

The carbon nanotubes loading in vinyl ester resin composites influenced the total particles production during the flaming combustion with changes during kinetics emission. Predominant populations of airborne particles generated during combustion of all tested composites were characterized by a $\mathrm{PN}_{50}$ following by $\mathrm{PN}_{100-500}$.

Keywords:

Cone calorimeter

Combustion

Aerosol released

Composites

Nanoparticles

\section{Introduction}

The use of composite materials for aeronautic and naval applications becomes widespread nowadays. Epoxy resins are widely used as matrices in advanced composites, due to their good impregnation and adhesion to fiber reinforcement. This results in exceptional mechanical performance, chemical and electrical resistance and low shrinkage during production. Their technical advantages com-

\footnotetext{
* Corresponding author.

E-mail address: carine.chivas-joly@lne.fr (C. Chivas-Joly).
}

pensate their relatively high costs compared to other thermosetting polymers, e.g. in aviation industry [1]. Composites have the potential to reduce the mass of vehicles, and thus fuel consumption and to contribute to the improvement of some other characteristics like mechanical strength and stiffness [2].

However, the flammability of composites still represents limitation in structural applications as an incidental fire event, including post-crash fire, which involves not only health risks but also loss of mechanical properties [3,4]. At higher temperatures, the organic matrix of composites decomposes with release of gaseous species and aerosols containing nano-objects and fibers. Health risk, toxicity effect and key mechanism for inhalation exposure associated 
to such released nano-objects remain poorly understood [5]. Combustion is the primary source of organic particles [6], characterized by an upper size between 100 and $200 \mathrm{~nm}$, that are indicated as the most impacting for human health [7-9]. In case of aircraft fires, rescue service, persons involved in an accident, cleanup personnel, and investigators are exposed to the airborne fibers and nanoparticles that may be released from composites burning and debris. Since the late 80s, when advanced composite materials started to be use in aircrafts, the post-crash reports highlights the fact that working on an airplane disaster site, even after several days, members of the recovery team start to experience increasing discomfort including sore eyes, throat and chests, skin irritation, and markedly reduced exercise capacity $[6,10]$. In the same way, the use of advanced composite materials in naval ships has been increasing for the last ten years and the possible effects on crew in case of fire should be investigated.

According to the literature few studies provided results on nanoobjects fire released from a fire [11,12]: a US research project carried by NIST [13], a french research projects NANOFEU $[14,15]$ and a study on release of airborne carbon nanotubes from burning composites [16]. The present study was performed in the framework of the DACOFEU project that intends to understand and characterize the production of aerosols and gases from the combustion of aircraft and naval structural composite materials.

According to the ISO 29,904:2013 standard [17], the measurable parameters of aerosols are particle size (equivalent diameters such as aerodynamic and electrical mobility diameters), particle shape (morphology) and aerosol size distribution. Currently used aerosol measurement methods are based on multi-metric, director indirect-read and time-integrated instruments to identify process of specific emissions [18]. Their complementary character allows for a complex aerosol analysis.

This paper presents results concerning particles emission from structural composites combustion, based on real-time and off-line aerosol measurements.

Concerning off-line measurements, particle mass size distributions, total particle mass and particle morphology were determined, while total number concentrations and number concentration of size class were measured in real-time for epoxy resin and vinyl ester composites materials. The role of the nature of polymer matrix, fibers and carbon nanotubes as well as glass reinforcements was investigated. The scope of this work was to examine the impact of such material features on the number concentration measurement of submicrometric particles and on particle mass distribution for diameter below $10 \mu \mathrm{m}$.

\section{Experimental setup}

The experimental set-up (Fig. 1) used during this study consists of a cone calorimeter coupled to the particle measuring instruments.

An open FTT (fire testing technology) cone calorimeter consists in an insulated line in which the produced combustion aerosol is sampled with a probe specially dimensioned for isokinetic samples. By maintaining the cone calorimeter effluent temperature at $100^{\circ} \mathrm{C}$, a first heated sampler-diluter system (Dekati DI1000 Diluter), also heated at $100^{\circ} \mathrm{C}$ is used to sample produced aerosols with a dilution ratio of 10 , and by limiting thermophoresis and condensation of the gaseous phase on the particle phase. Downstream this dilution stage, the combustion aerosol is sampled by a DLPI system (Dekati Low Pressure Impactor) which samples particles between $30 \mathrm{~nm}$ and $10 \mu \mathrm{m}$ on impaction substrates (polycarbonate filters). A second dilution stage is used to dilute the aerosol at ambient temperature with a dilution ratio of 10 , leading to a total dilution ratio of 100.This additional dilution is necessary in order to avoid
Table 1

Instrument description and experimental conditions.

\begin{tabular}{|c|c|c|}
\hline & Instruments & Experimental conditions \\
\hline Fire device & $\begin{array}{l}\text { FTT (fire testing } \\
\text { technology) } \\
\text { cone calorimeter }\end{array}$ & $\begin{array}{l}\text { Sample mass }=2.50 \mathrm{~g} \text {, } \\
\text { Set temperature }=900{ }^{\circ} \mathrm{C} \text {, } \\
\text { Thermal flux }=75 \mathrm{~kW} / \mathrm{m}^{2} \text {, } \\
\text { Total air flow }=160 \mathrm{~L} / \mathrm{min} \text {, } \\
\text { Air composition }=21 \% \mathrm{O}_{2} \\
( \pm 1 \%) \text {, }\end{array}$ \\
\hline \multirow[t]{2}{*}{$\begin{array}{l}\text { Dilution } \\
\text { Systems }\end{array}$} & Dekati DI1000 diluter & $\begin{array}{l}\text { Dilution ratio }=10 \text {, } \\
\text { Sample flow rate }=5 \mathrm{~L} / \mathrm{min} \text {, } \\
\text { Number of diluters }=1 \text {, } \\
\text { Dilution } \\
\text { temperature }=100{ }^{\circ} \mathrm{C}\end{array}$ \\
\hline & Palas VKL10 diluter & $\begin{array}{l}\text { Dilution ratio }=10, \\
\text { Sample flow rate }=5 \mathrm{~L} / \mathrm{min} \text {, } \\
\text { Number of diluters }=1 \text {, } \\
\text { Dilution temperature }= \\
\text { ambient temperature }\end{array}$ \\
\hline \multirow[t]{2}{*}{$\begin{array}{l}\text { On-line } \\
\text { measure- } \\
\text { ment }\end{array}$} & $\begin{array}{l}\text { DMS } 500 \text { cambustion M85 } \\
\text { Fast particle analyzer } \\
\text { (Dynamic particle } \\
\text { spectrum) }\end{array}$ & $\begin{array}{l}\text { Sample flow rate }=8 \mathrm{~L} / \mathrm{min} \text {, } \\
\text { Range }=5 \mathrm{~nm}-1 \mu \mathrm{m} \text {, }\end{array}$ \\
\hline & $\begin{array}{l}\text { Aerodynamic particle sizer } \\
\text { (APS 3321, TSI) } \\
\text { Condensation particle } \\
\text { counter } \\
\text { (CPC 3022, TSI) }\end{array}$ & $\begin{array}{l}\text { Sample flow rate }=5 \mathrm{~L} / \mathrm{min} \text {, } \\
\text { Range }=0.6 \mu \mathrm{m}-20 \mu \mathrm{m} \text {, } \\
\text { Sample flow } \\
\text { rate }=0.3 \mathrm{~L} / \mathrm{min} \text {, } \\
\text { Range }=7 \mathrm{~nm}-1 \mu \mathrm{m} \text {, } \\
\text { Solvent = butanol }\end{array}$ \\
\hline \multirow[t]{2}{*}{$\begin{array}{l}\text { Off-line } \\
\text { measure- } \\
\text { ment }\end{array}$} & $\begin{array}{l}\text { Dekati low pressure } \\
\text { impactor (DLPI) }\end{array}$ & $\begin{array}{l}\text { Sample flow } \\
\text { rate }=10 \mathrm{~L} / \mathrm{min} \text {, } \\
\text { Impactor } \\
\text { temperature ambient } \\
\text { temperature, } \\
\text { Pressure }=100 \mathrm{mbar} \text {, } \\
\text { Range }=30 \mathrm{~nm}-\mu \mathrm{m}, 13 \\
\text { stages } \\
\text { Impaction } \\
\text { substrates = polycarbonate } \\
\text { filters }\end{array}$ \\
\hline & $\begin{array}{l}\text { Scanning electron } \\
\text { microscope (FEG-SEM, } \\
\text { Zeiss Ultra plus) }\end{array}$ & $\begin{array}{l}\text { Electronic probe diameter } \\
1.7 \mathrm{~nm} \text { for an accelerating } \\
\text { voltage between } 0.2 \mathrm{kV} \text { and } \\
1 \mathrm{kV} \text {. }\end{array}$ \\
\hline
\end{tabular}

instrumental saturation due to high particle concentrations. Table 1 presents the experimental conditions with associated parameters. These operating conditions were applied for all combustion tests and for all samples. Knowing that, at least three tests were performed for each sample. Dilution ratios, measurement ranges and experimental set-up were implemented in order to have the same experimental conditions between composite materials.

Concerning real-time particle analysis, a fast particle analyzer (Dynamic Particle Spectrum, DMS 500, Cambustion) and an aerodynamic particle sizer (APS 3321, TSI) were used to measure the particle-size number distribution for particles between $5 \mathrm{~nm}-1 \mu \mathrm{m}$ and $0.06 \mu \mathrm{m}-20 \mu \mathrm{m}$ respectively.

A butanol-Condensation Particle Counter (CPC 3022, TSI) was also used in real time to measure the total particle number concentration of particles sized between $7 \mathrm{~nm}$ and $1 \mu \mathrm{m}$.

For off-line analyses, the combustion aerosols were sampled at ambient temperature on impaction substrates (polycarbonate filters) placed in a DLPI low pressure cascade impactor (Dekati, serie 2465 consisting of 13 impaction stages. Impaction substrates (polycarbonate filters) were weighted before and after each experiment in order to determine the particle mass deposited by size range (from $30 \mathrm{~nm}$ to $10 \mu \mathrm{m}$ ). In order to investigate the particle morphology, a scanning electron microscope (FEG-SEM, Zeiss Ultra Plus) was used. 


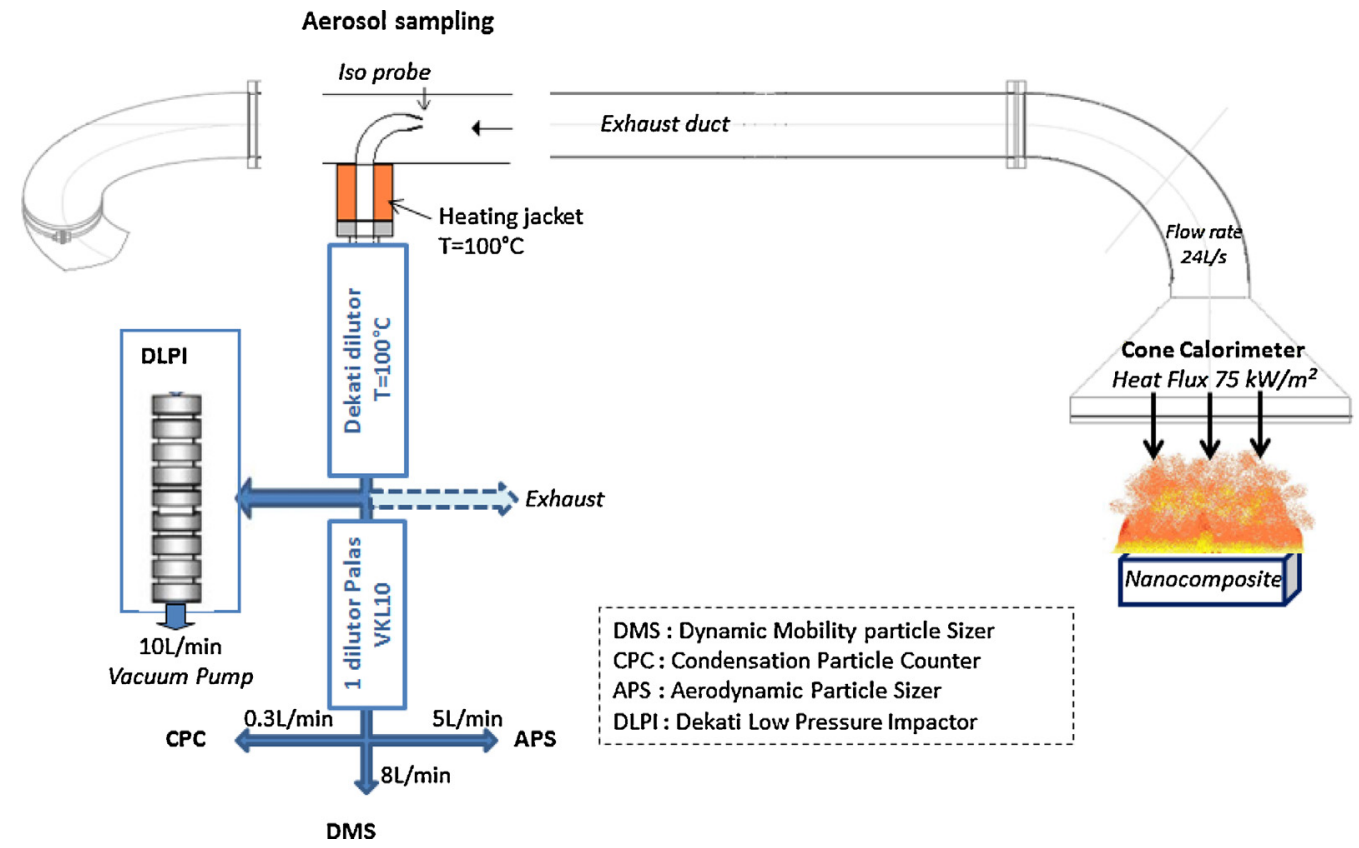

Fig. 1. Experimental set-up.

\section{Composite materials}

The selection of composite materials was based on two criteria: (i) the material behavior when submitted to a combustion representative of a post-crash fire (the shortest burnthrough time and the highest level of damage), and (ii) yield of the total smoke release during fire exposure (the highest level and presence of flying soot and fibers). Various materials were tested from civil and military applications for aircrafts, helicopters and naval ships. Different resins (epoxy resin and vinyl ester) and fibers orientations (unidirectional or interlaced) were examined in order to reproduce realistic post-crash fire scenarios. The fire behavior under defined fire conditions was studied using both, the FTT cone calorimeter (heat flux of $75 \mathrm{~kW} \mathrm{~m}^{-2}$ ) [18] and the burnthrough test [19]. The burnthrough test refers to the penetration of an external post-crash fuel fire into an aircraft cabin interior [20,21]. This test was performed using a NexGen kerosene burner designed by the Federal Aviation Administration (FAA) which generates a turbulent flame around $1038^{\circ} \mathrm{C}\left(180 \mathrm{~kW} \mathrm{~m}^{-2}\right)$.

The total smoke production obtained from FTT cone calorimeter was correlated to the orientation of fibers, the nature of polymeric materials (various Epoxy resin (A, B, C) with fire resistance of 120 or $180 \mathrm{~min}$ ) and the rate of damage done during the burnthrough experiments.

Carbon fibers alone (MAT 1) tested during selection of composites materials were not studied specifically in the following. An epoxy resin (Epoxy resin A) was used alone (MAT2) as home-made formulation. It was developed to understand the own contribution of the polymer matrix.

Two aircraft structural composites based on epoxy resin matrix were selected. Epoxy matrices were formulated with different curing agents.

The first composite, (MAT 3) is made of the epoxy resin B with interlaced carbon fibers, was characterized by:

- A maximum damage (100\% burnthrough) at the center of the testing composite impacted by the flame.

- The disappearance of fibers due to thermal-oxidation phenomena or fibers breaking and dispersion of fibers in the test enclosure.

The second composite selected (MAT 4) is made of the epoxy resin $C$ with unidirectional carbon fibers, that presents a rate of damage at $85 \%$ during the burnthrough test and a production of significant amount of smoke, volatile soot and fibers deposited around the fire device.

To better understand the temporal evolution of aerosol emitted during combustion of both selected materials (MAT4 and MAT5), additional materials (MAT 6, 7 and 8) were tested to evaluate the influence of (i) another organic matrix (vinyl ester resin,), (ii) weight percentage of carbon nanotubes ( $1 \mathrm{wt} . \%$ as representative commercial application and $5 \mathrm{wt} . \%$ as maximal loading) to check the potential risk of emission, (iii) the presence of reinforcement

Table 2

Composites materials description.

\begin{tabular}{|c|c|c|c|}
\hline Sample & Organic matrix & Nano-objects & Reinforcement \\
\hline MAT1 & - & Carbon fibers & \\
\hline MAT2 & Epoxy resin $\mathrm{A}^{\mathrm{a}} 120^{\mathrm{b}}$ (100 wt.\%) & - & - \\
\hline MAT3 & Epoxy resin $\mathrm{A}^{\mathrm{a}} 120^{\mathrm{b}}$ (50 wt.\%) & Interlaced Carbon fibers & - \\
\hline MAT4 & Epoxy resin $\mathrm{B}^{\mathrm{a}} 120^{\mathrm{b}}$ (38 wt.\%) & Interlaced Carbon fibers & - \\
\hline MAT5 & Epoxy resin $C^{\mathrm{a}} 180^{\mathrm{b}}$ (29 wt.\%) & Unidirectional Carbon fibers & - \\
\hline MAT6 & Vinyl ester resin (35 wt.\%) & - & Glass fibers \\
\hline MAT7 & Vinyl ester resin (34 wt.\%) & Carbon nanotubes (1 wt.\%) & Glass fibers \\
\hline MAT8 & Vinyl ester resin (30 wt.\%) & Carbon nanotubes (5 wt.\%) & Glass fibers \\
\hline
\end{tabular}

a Epoxy resins references as A, B, C are used to distinguish different types of epoxy resins.

b Epoxy resin with fire resistance of 120 or $180 \mathrm{~min}$, respectively. 


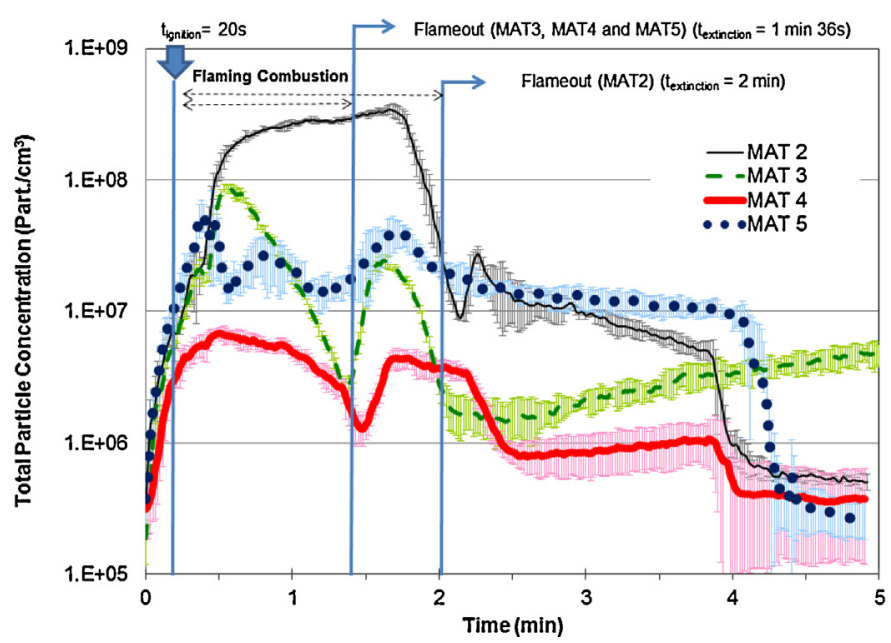

Fig. 2. Time evolution of the particle number concentration of the combustion aerosols measured by the CPC 3022, for the epoxy resin composites (MAT 2-Epoxy resin A120, MAT 3-Epoxy resin A120/ carbon fibers, MAT 4-Epoxy resin B 120/ carbon fibers and MAT 5-Epoxy resin C180/ carbon fibers).

materials (glass fibers) on airborne nanoparticles generation. The summary of samples composition is shown in Table 2.

The composite sample size was fixed at $50 \mathrm{~mm} \times 50 \mathrm{~mm} \times$ $2.5 \mathrm{~mm}$ corresponding to 7 and $12 \mathrm{~g}$ of epoxy materials and vinyl ester resins respectively.

\section{Results and discussions}

\subsection{Total particle number concentration}

\subsubsection{Epoxy resin/carbon fibers composites}

The time evolution of the total particle number concentrations emitted with the epoxy resins/carbon fibers were measured with the CPC 3022 and are shown in Fig. 2. Three different time phases are identified: (1) ignition, (2) flaming combustion and (3) composite flameout. For each material, the related uncertainty represents the standard deviation calculated on three measurements.

During the combustion process, the flame appears from the 20 first seconds (phase 1: ignition-Fig. 2) characterized by a fast increase of the particle number concentration. During the flaming combustion phase, the results show predominance in terms of particle generation for the epoxy resin alone (MAT2) with a maximum number concentration of $3.5 \times 10^{8}$ part $/ \mathrm{cm}^{3}$ compared to epoxy composites that contain carbon fibers.

For composite materials containing carbon fibers (MAT 3 and MAT 4) with identical carbon fibers orientation, maximum particle concentrations are respectively equal to $9.10^{7}$ and $7.10^{6}$ part $/ \mathrm{cm}^{3}$. For both compositions, the reduction of particle concentrations emitted underlines the role of carbon fiber in term of reduction of the matrix thermal degradation. Combustion of materials MAT 3 and MAT 4 which contains unidirectional carbon fibers are characterized by an earlier flameout phase followed by a stronger particle number concentrations increase. Between ignition and flameout phases, the material MAT 5 presents a particular time evolution, i.e. the emitted aerosol is characterized by two successive peaks with maximum concentrations of $6.10^{7}$ and $3.10^{7}$ part $/ \mathrm{cm}^{3}$ respectively. This different behavior could be explained by the presence of oxygen, which could penetrate more easily between the unidirectional fibers than between interlaced ones [22] and thus enhanced matrix thermal degradation compared to other materials.

Downstream the flameout phase, combustion is stopped and a fast increase in total particle concentration was measured for MAT 3 and MAT 4 at $t=1 \mathrm{~min} 30 \mathrm{~s}$ and at $t \sim 2 \min$ for MAT 2 . Only MAT 5

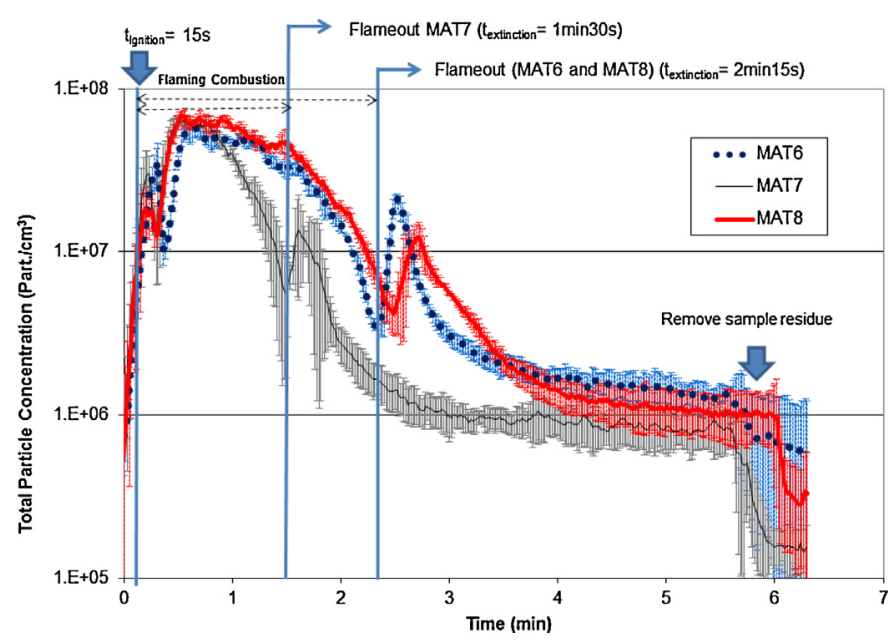

Fig. 3. Time evolution of the particle number concentration of the combustion aerosols measured by the CPC 3022, for the vinyl ester resin composites (MAT 6 , vinyl ester/glass fibers, MAT 7, Vinyl ester/ Glass fibers/ 1\%wt. Carbon Nanotubes and MAT 8, Vinyl ester/ Glass fibers/5\% wt. Carbon nanotubes).

does not exhibit this concentration increase. This strong increase is then followed by a concentration decrease until a stationary phase for all materials.

Total particle number concentrations emitted depend on the formulation of the epoxy resin, on the presence of reinforcements (in comparison between MAT2 and MAT3) and on their orientation in the composite material (e.g. MAT3, MAT4 and MAT5). These differences can be explained by the modifications in the composite material thermal properties during combustion as the formation of a barrier layer that limits oxygen and combustibles diffusion as well as heat transfers. Kashiwagi et al. [23-25] found that carbon nanotubes improve flame resistance by the formation of a protective nanotube network structure. They act as a heat shield for composites [26]. Consequently, a lesser barrier effect in case of unidirectional carbon fibers can lead to a modification of fire behavior and aerosol emission in comparison with interlaced structure.

\subsection{Vinyl ester/glass fibers/carbon nanotubes composites}

The time evolution of the total particle number concentrations emitted by the vinyl ester resins/glass fibers/carbon nanotubes is shown in Fig. 3. As for epoxy composites, the three main time phases of the combustion process are noticed and the related uncertainty represents the standard deviation calculated on three measurements.

During the ignition phase $(t<15 \mathrm{~s})$, materials are characterized by maximum particle number concentrations of $3.10^{7} \mathrm{part} / \mathrm{cm}^{3}$ for MAT 6 and MAT 7 and of $2.10^{7}$ part $/ \mathrm{cm}^{3}$ for MAT 8 . For $t>15 \mathrm{~s}$ (phase 2, flaming combustion), an increase of particle concentration was measured for the three composite materials, with a maximum concentration of $6.10^{7}$ part $/ \mathrm{cm}^{3}$. For $t=1 \mathrm{~min}$, only MAT 7, which contains only $1 \%$ of carbon nanotube in mass presents a fast particle concentration decreasing. This can be explained by the presence of a mass barrier and thermal shielding effect which reduces particle generation and foster flameout phase at $1 \mathrm{~min} 30 \mathrm{~s}$. The MAT 8 composite, composed by $5 \mathrm{wt} . \%$ of carbon nanotube, is characterized by a similar behavior than the matrix alone (MAT 6). This can be explained by an antagonistic effect due to a too high percentage of carbon nanotubes, which increases strongly the thermal conductivity of composite, leading to enhanced matrix degradation [23]. Downstream the flameout phase, the combustion is stopped and a fast particle concentration increase was measured at $t=1 \mathrm{~min} 30 \mathrm{~s}$ 

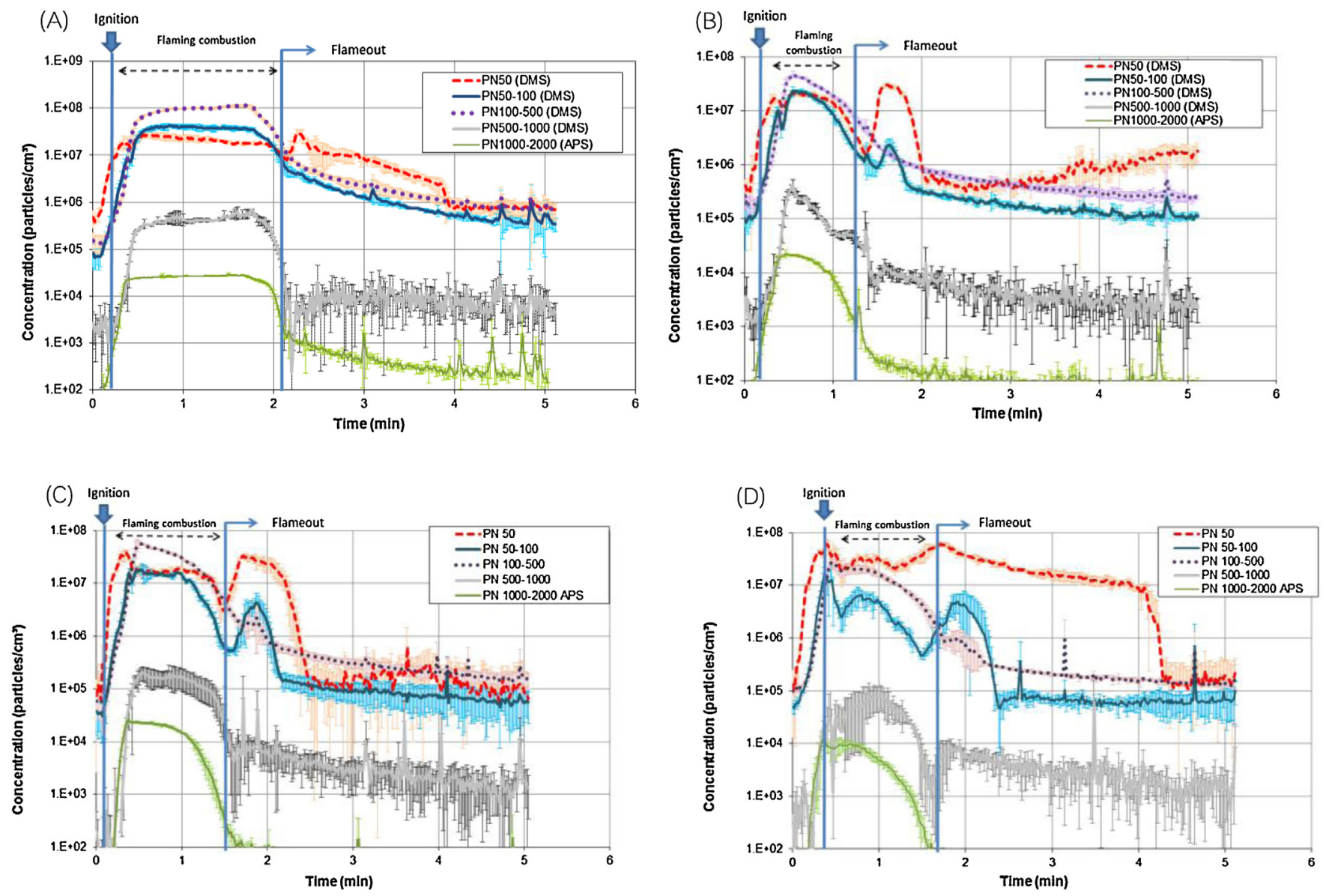

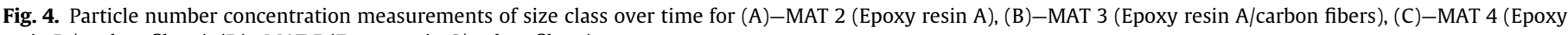
resin B / carbon fibers), (D)-MAT 5 (Epoxy resin C/carbon fibers)

for MAT 7 and at $t=2 \min 20 \mathrm{~s}$ for MAT 6 and MAT 8, followed by a decrease until a stationary phase for all materials.

As shown by several works [27-29], carbon nanotubes could lead to a strong decrease in the peak of heat release rate (pHRR) even at very low content of CNTs, due to thermal barrier effect, radical trapping, and re-radiation of heat. Better dispersion of the CNTs can be achieved for lower mass rates than $1 \mathrm{wt} . \%$, resulting in a decrease of pHRR. The dispersion and the low rate of carbon nanotubes inside the composite play an important role by reducing the potential emission of particles. Moreover, this study highlights that the total particle number concentration generated from the composites combustion differs in function of the loading of the carbon nanotubes. An optimum value of CNTs (possibly close to $1 \mathrm{wt} . \%$ ) could correspond to a good dispersion as well as a minimum potential emission of particles.

\subsection{Real-time measurement of particle number concentration of size classes}

Figs. 4 and 5 present the time evolution of particle number concentrations of size classes measured using DMS and APS for the epoxy resin/carbon fiber composites and vinyl ester/glass/carbon nanotube composites respectively.

On each graph, size classes $\mathrm{PN}_{x-y}$ measured by DMS are defined as the sum of the number concentrations (in part $/ \mathrm{cm}^{3}$ ) of particles which diameter lies between $d_{x}=x \mathrm{~nm}$, and $d_{y}=y \mathrm{~nm}$ and which are emitted during combustion of composites. It is important to note that DMS performs measurements of electrical mobility diameter while the aerodynamic diameter measurements are determined using APS. Both types of diameter can be easily compared when spherical particles are considered. Even if, the combustion aerosols obtained for the various composites are characterized by non-spherical particles (see section on particle morphology), the equivalence between the both diameters is more complex and required for example the effective density for the agglomerate/aggregate particles. Authors purpose for readability that the results of both APS and DMS measurements are presented on the same figure.

Prior to ignition phase $(t<20 \mathrm{~s})$, the particles emitted were mainly classified as $\mathrm{PN}_{50}$ during the combustion of all composite materials.

Concerning epoxy resin materials, the ignition phase is followed by the composite flaming combustion after $20 \mathrm{~s}$. Concerning MAT 2 combustion, this phase was characterized by a plateau at CPC measurements which mainly corresponds to an emission of particles in the 100-500 nm range ( $\left.\mathrm{PN}_{100-500}\right)$. For MAT 3 and MAT 4 with interlaced carbon fibers, the flaming combustion corresponds mainly to an emission of $\mathrm{PN}_{100-500}$ particles. Concerning the MAT 5 material, which presents a reinforcement made of unidirectional carbon fibers, its combustion leads mostly to $\mathrm{PN}_{50}$ particles for during the three phases. During composite flameout, composite materials reemit PN 50 particles, regardless of the presence and orientation of carbon fibers. For materials MAT 3, MAT 4 and MAT 5, the particle production rate of emission ranging between 1 and $2 \mu \mathrm{m}$ and measured by the APS follows the same evolutions in terms of particle number concentration. For MAT 2, the rate of emitted particle is directly related to the combustion time of the composite, characterized by a longer flameout phase than for MAT 3, 4 and 5. Moreover, 

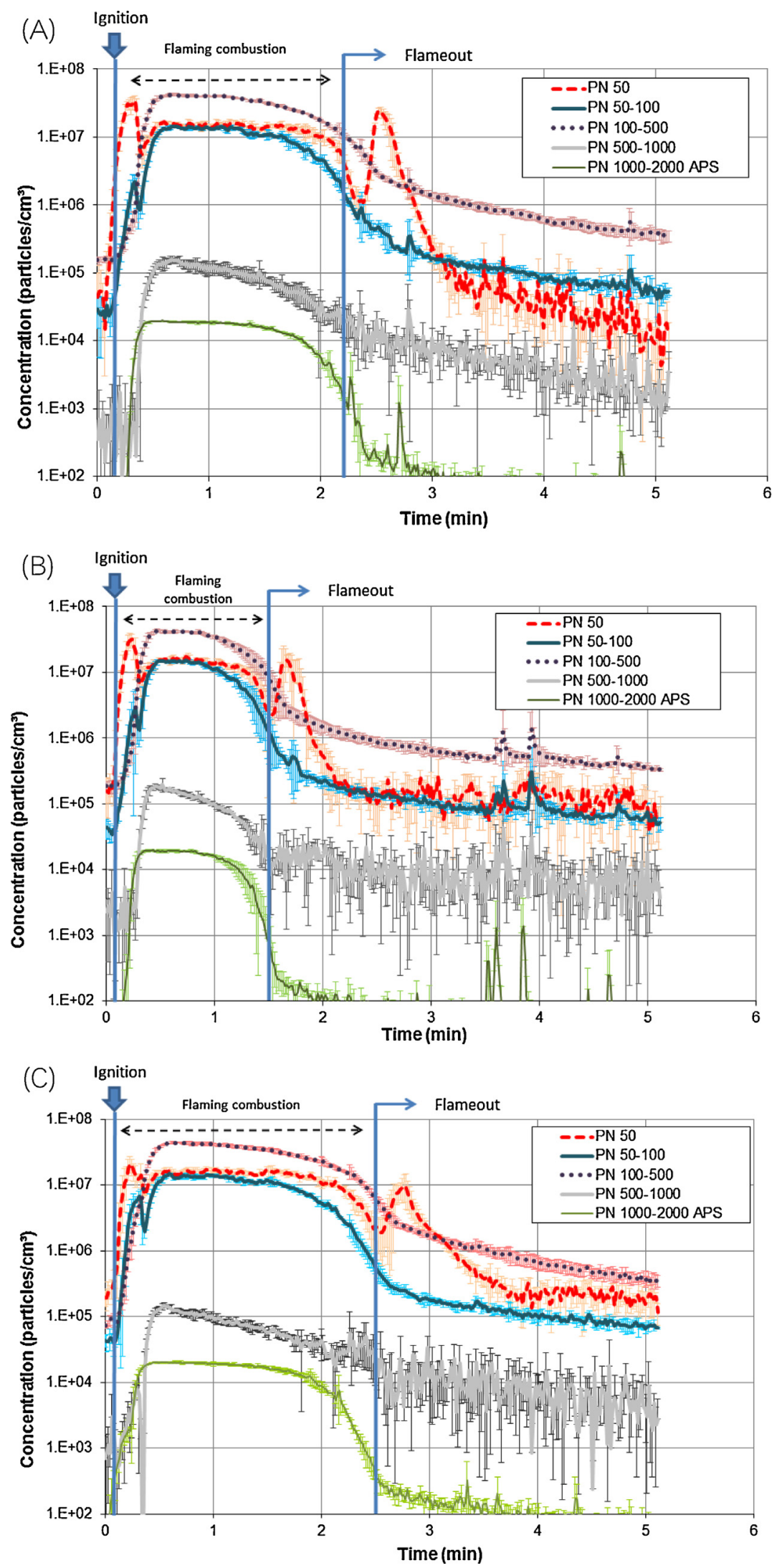

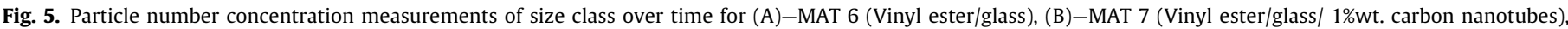
(C)-MAT 8 (Vinyl ester/glass / 5\%wt. carbon nanotubes). 
Table 3

Total particle mass and associated yield obtained during combustion or each material type.

\begin{tabular}{|c|c|c|c|c|}
\hline Material & Matrices & Total particle mass(mg) & Mass yield( mg g $\left.^{-1}\right)$ & Relative expanded uncertainty $(U=2 \mathrm{k}, \%)$ \\
\hline MAT 2 & Epoxy resin & 1.77 & 0.16 & 12.3 \\
\hline MAT 3 & Epoxy resin/interlaced & 0.45 & 0.14 & 50.3 \\
\hline MAT 4 & Epoxy resin/interlaced & 0.34 & 0.11 & 54.3 \\
\hline MAT 5 & Epoxy resin/unidirectional & 0.41 & 0.18 & 60.8 \\
\hline MAT 6 & Vinyl ester-glass & 0.89 & 0.20 & 21.7 \\
\hline MAT 7 & Vinyl ester-glass $/ 1 \% \mathrm{CNT}$ & 0.52 & 0.16 & 38.7 \\
\hline MAT 8 & Vinyl ester-glass/5\% CNT & 1.01 & 0.19 & 22.8 \\
\hline
\end{tabular}

the particles emissions for MAT 2 show a major contribution of PN50 particles after the flameout phase.

Concerning vinyl ester composites, a first concentration peak was observed at the beginning of the flaming combustion phase with the CPC measurements (Fig. 3). The DMS measurements indicate that $\mathrm{PN}_{50}$ particles mainly contributed to this event (Fig. 5). During the composite flaming combustion ( $t \sim 2 \min 20 \mathrm{~s}$ ), similar behaviors were observed between MAT 6 and MAT 8 regarding particle number concentration emitted for specific size classes, with a predominant emission of PN 100-500. MAT 7 presented a reduced flameout time, which can be ascribed to the formation of a barrier layer and thermal shielding effect of well-dispersed CNTs. The particle emission rate was similar as MAT 6 and MAT 8. For these three materials (MAT 6, MAT 7, MAT 8), the relative concentrations associated to each size class during combustion time were similar. Moreover, the particles emissions for each of this three vinyl ester nanocomposites, show a major contribution of $\mathrm{PN}_{50}$ particles after the flameout phase.

\subsection{Particle-size mass distributions}

The particle-size mass distribution of the particles was obtained by measuring the particle mass deposited on every impaction stage of the DLPI, with an accuracy of $10 \mu \mathrm{g}$. The particle-size mass distribution uncertainties were estimated using an error propagation law by taking into account three measurements. Fig. 6 presents logarithmic representations of mass distributions in function of particle aerodynamic diameter $\left(d_{\mathrm{a}}\right)$ for each studied material. The $Y$ axis $\left(\mathrm{dM} / \mathrm{M}_{0} d \log \mathrm{d}_{\mathrm{a}}\right)$ represent the mass of the collected particles divided by the measurement channels width in log scale. For each material, the error bars represent the associated uncertainty $(U=2 \mathrm{k})$.

For each Epoxy resin materials (Fig. 6A-D), the particle-size mass distribution is characterized by a modal diameter of $320 \mathrm{~nm}$ (channel $\mathrm{n}^{\circ}$ ). The masses associated to these modal diameters for each material are of $2.10^{-2} \mathrm{~g}$ (MAT 2), $5.10^{-3} \mathrm{~g}$ (MAT 3) and $4.10^{-3} \mathrm{~g}$ (MAT 4 and MAT 5).

Combustion aerosols emitted by vinyl ester resin (Fig. 6E-G) are characterized by a similar population of particles for all the composites in terms of particle-size mass distribution on each impaction stage, when associated uncertainty is considered. In a previous work, Chivas-Joly et al. [5] reported no significant differences in mass size distribution of aerosols between PA-6 and PA-6/CNTs nanocomposites. For each vinyl ester materials, the particle-size mass distributions are characterized by a mode (channel No. 5) with a cut-off diameter $D_{50 \%}$ of $320 \mathrm{~nm}$, as for epoxy resin. The masses associated to these modes for each of the three materials are of $9.10^{-3} \mathrm{~g}$ (MAT 6 and MAT 8) and of $4.10^{-3} \mathrm{~g}$ (MAT 7). These results are in accordance with the results obtained with the $\mathrm{CPC}$, where the presence of $1 \%$ of carbon nanotube (MAT 7) reduces the particle emission compared to MAT 6 and MAT 8.

Fig. 7 shows the respective cumulative mass fractions of epoxy and vinyl ester composites. The $50 \%$ cumulative mass fractions correspond to $260 \mathrm{~nm}$ for MAT 4 and MAT 5 and to $380 \mathrm{~nm}$ for MAT 3 and MAT 2. For ultrafine particles (below $0.1 \mu \mathrm{m}$ ), all the compos- ites are characterized by a cumulative mass fraction between 5 and $20 \%$, by considering the associated standard deviations.

When comparing the cumulative mass fraction of epoxy resins (MAT 2-resin alone) and MAT 3 to MAT 5 (epoxy resin and carbon fibers), it seems that there are significant differences, but it is difficult to explain them, regarding the presence of carbon fibers, particularly for the amount of submicronic particles. The cumulative mass fractions of $50 \%$ range from $380 \mathrm{~nm}$ (MAT 8) to $600 \mathrm{~nm}$ (MAT 7).

For ultrafine particles (below $0.1 \mu \mathrm{m}$ ), if the associated standard deviations are considered, all the composites show a cumulative mass fraction less than $10 \%$.

\subsection{Total particle mass and morphology}

The total particle mass obtained by DLPI measurements and associated yield are presented in Table 3 with the relative expanded uncertainties.

The mass yield related to the presence of unidirectional carbon fibers (MAT 5) $\left(0.18 \mathrm{mg} \mathrm{g}^{-1} \pm 60.8 \%\right)$ is comparable to the mass yield of interlaced carbon fibers for MAT $3\left(0.14 \mathrm{mg} \mathrm{g}^{-1} \pm 50.3 \%\right)$ and for MAT4 (0.11 $\mathrm{mg} \mathrm{g}^{-1} \pm 54.3 \%$ ).

As for vinyl ester resin composites, the use of carbon nanotubes does not impact the emitted particles mass for vinyl ester / glass matrix materials with $0.20 \mathrm{mg} \mathrm{g}^{-1} \pm 21.7 \%$ (MAT 6), $0.16 \mathrm{mg} \mathrm{g}^{-1} \pm 38.7 \%$ (MAT 7) and $0.19 \mathrm{mgg}^{-1} \pm 22.8 \%$ (MAT 8), considering the associated relative uncertainty.

Whatever the nature of the reinforcements incorporated in the matrices, there is no significant variation of the total aerosol yield. This phenomenon was yet noticed in the case of PMMA based CNTs nanocomposites [5]. This was also confirmed by morphology study. Indeed, more than one hundred images were made using SEM at several magnifications. The most representative ones are presented on Fig. 8 for epoxy resin with carbon fibers and vinyl ester with carbon nanotubes. Whatever the matrices and the reinforcement used, aggregates/agglomerates composed of pseudo-spherical primary particles are observed. Contrary to the observations made in the Nanofeu project [5] concerning PA6 filled with nanotubes submitted to an irradiation of $50 \mathrm{~kW} / \mathrm{m}^{2}$ and where nanotubes were observed using AFM and SEM, here, due to burning conditions at the higher heat flux of $75 \mathrm{~kW} / \mathrm{m}^{2}$, neither carbon nanotube nor nanofiber were observed in the soot particles. One explanation to this observation is that nanotubes and nanofibers seem to be completely destroyed at such heat flux.

\section{Conclusions}

The measurement of particles emitted during combustion of various composite materials, regarding the potential emission associated with carbon fibers and carbon nanotubes, was performed using an experimental setup consisting of a cone calorimeter coupled with on-line and off-line aerosol metrology instruments.

The main data necessary for the health/safety risk assessment and for the modeling of the combustion aerosols dispersion in 
Epoxy resin / carbon fibers composites

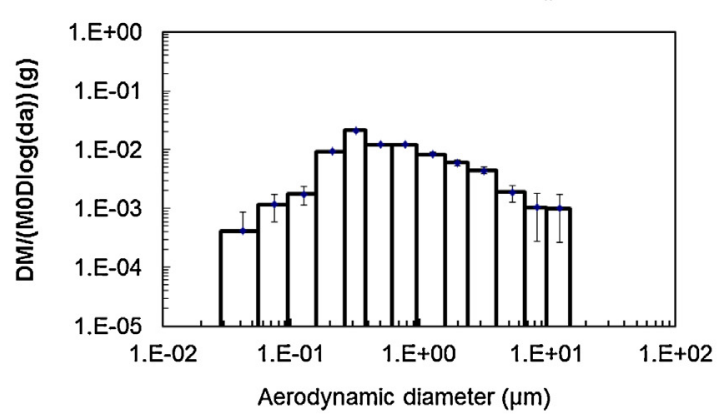

(A)

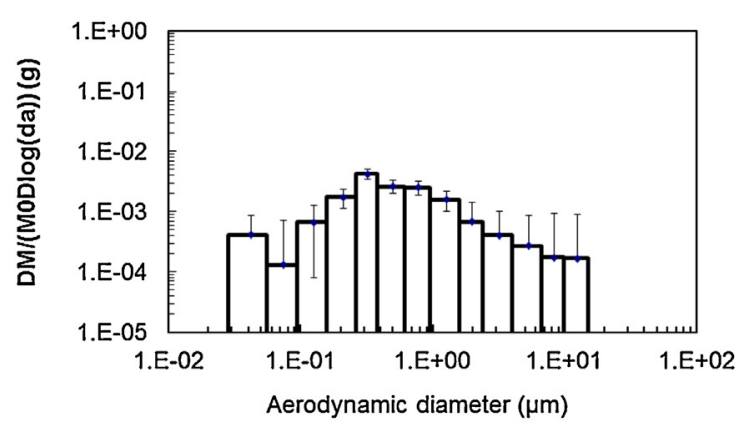

(C)

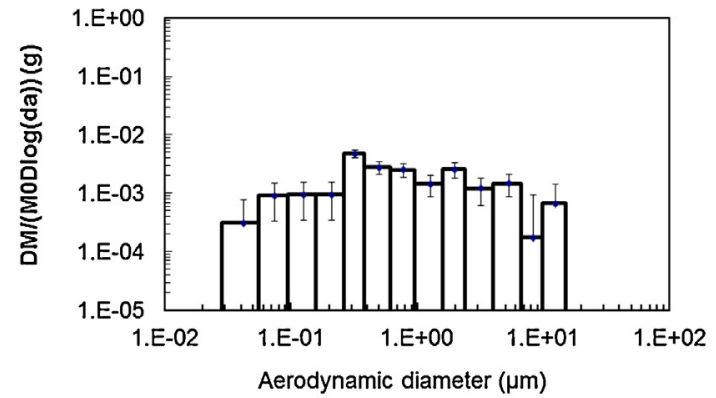

(B)

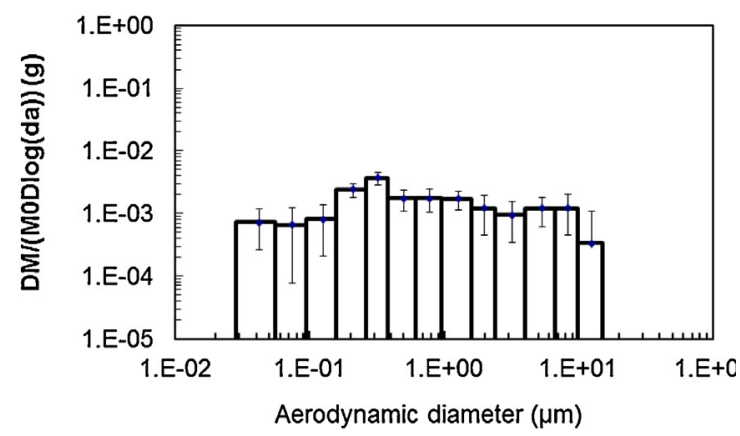

(D)

Vinyl ester / glass fibers/ carbon nanotubes composites

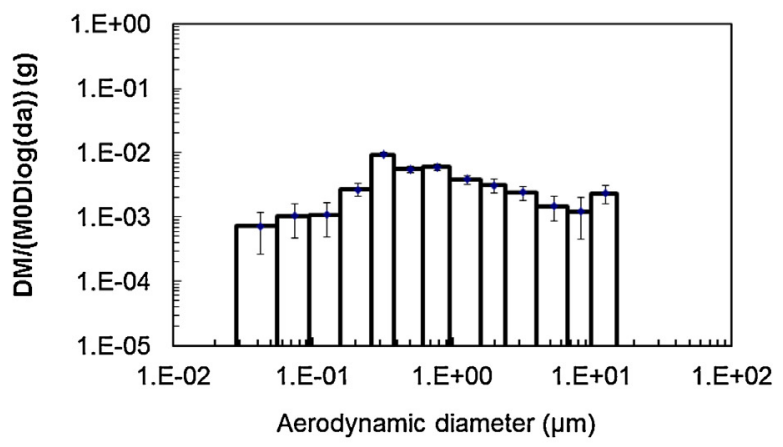

(E)

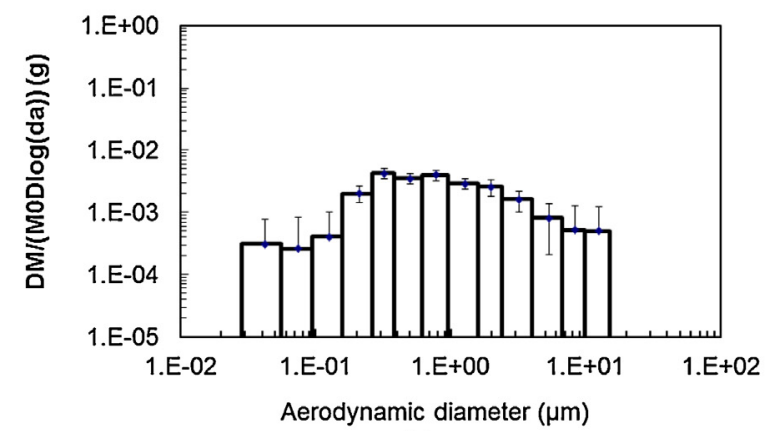

(F)

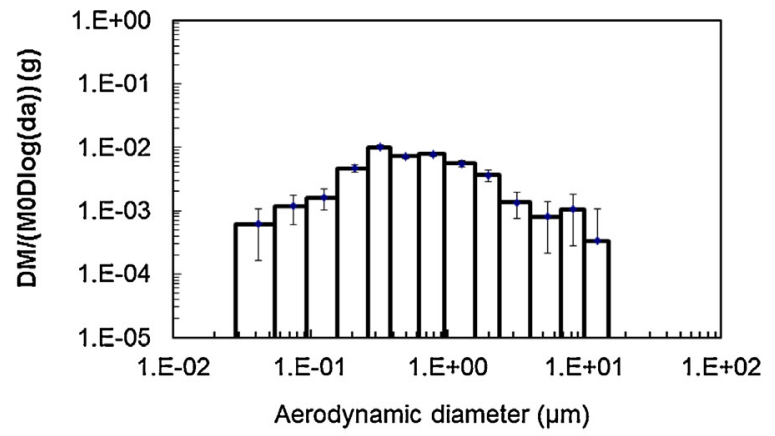

(G)

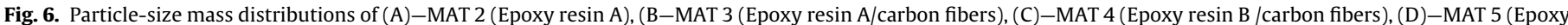
resin C/carbon fibers). (E)-MAT 6 (Vinyl ester/ glass), (F)-MAT 7 (Vinyl ester/ glass/1\% wt. NTC), and (G)-MAT 8 (Vinyl ester/ glass /5\% wt. NTC).

atmosphere, were considered in terms of total particle number concentration, particle-size mass distribution, real-time measurement of particle number concentration of size classes, total particle mass emitted, and particle morphology.

This study shows that the total particle number concentrations depend on the presence of reinforcements and on the orientation of the fibers in the composite material. These differences can be explained by the change in the composite material thermal properties during degradation: a barrier layer that limits oxygen and heat transfer is created.

For vinyl ester/glass composites, the evolution of the total particle number concentration is related to the presence of carbon nanotubes. The particle concentration decreases with the presence of $1 \mathrm{wt} . \%$ of carbon nanotube which corresponds to the creation of 

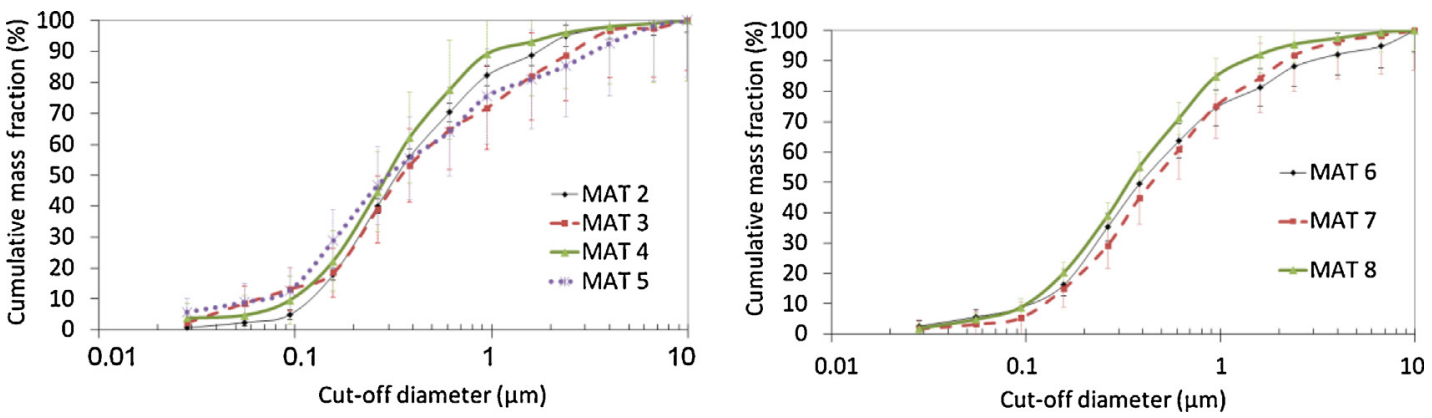

Fig. 7. Cumulative particle mass distribution of epoxy composites (a) and vinyl ester composites (b).
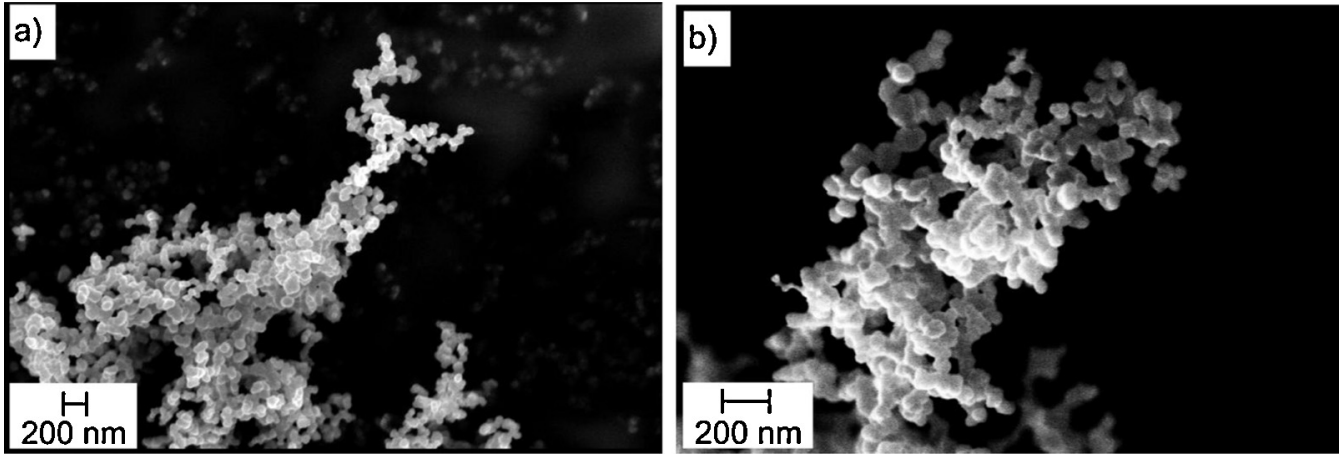

Fig. 8. SEM images obtained for the epoxy resin and vinyl ester composites: (a) MAT 4 (Epoxy resin B/carbon fibers) and (b) MAT 8 (vinyl ester/glass/5\% wt. CNT).

an effective barrier structure in the composite, which reduces the particle generation and fosters flame out.

For each composite material (epoxy resin and vinyl ester), the particle-size mass distribution is characterized by a mode with a cut-off diameter of $320 \mathrm{~nm}$. The presence of carbon nanotubes or carbon fibers does not impact the total particle mass emitted during combustion of vinyl ester/glass matrix and epoxy resin.

Prior to the ignition phase of the combustion process, the aerosols emitted by the composite materials were mainly characterized by particles classified as $\mathrm{PN}_{50}$. This phenomenon is followed by the composite flaming combustion, characterized by the emission of particles ranged between 100 and $500 \mathrm{~nm}\left(\mathrm{PN}_{100-500}\right)$ for all the materials except MAT 5 containing unidirectional fibers, for which the majority of particles emitted are $\mathrm{PN}_{50}$ particles.

\section{Acknowledgement}

The authors acknowledge the valuable comments received from G. Leroy from INERIS.

\section{References}

[1] A. Toldy, B. Szolnoki, G. Marosi, Flame reatardancy of fibre-reinforced epoxy resin composites for aerosol applications, Pol. Deg. Stab. 96 (2011) 371-376.

[2] E. Deletombe, D. Delsart, A. Kohlguber, F. Johnson, Improvement of numerical methods for crash analysis in future composite aircraft design, Aerosp. Sci. Technol. 4 (2000) 189-199.

[3] A.P. Mouritz, S. Feih, E. Kandare, Z. Mathys, A.G. Gibson, P.E. Des Jardin, S.W. Case, B.Y. Lattimer, Review of fire structural modelling of polymer composites, Compos. A-Appl. Sci. Manuf. 40 (2009) 1800-1814.

[4] B.K. Kandola, A.R. Horrocks, P. Myler, D. Blair, Mechanical performance of heat/fire damaged novel flame retardant glass-reinforced epoxy composites, Compos. A-Appl. Sci. Manuf. 34 (2003) 863-873.

[5] C. Chivas-Joly, E. Guillaume, S. Ducourtieux, L. Saragoza, D. Lesenechal, J.-M. Lopez-Cuesta, C. Longuet, R. Sonnier, S. Duplantier, J.P. Bertrand, D. Calogine, B. Minisini, D. Parisse, Influence of carbon nanotubes on fire behaviour and aerosol emitted during combustion of thermoplastics, Fire Mater. (2012), http://dx.doi.org/10.1002/fam.2161.

[6] T.C. Bond, D.G. Streets, K.F. Yarber, S.M. Nelson, J.-H. Woo, Z. Klimont, A technology-based global inventory of black and organic carbon emissions from combustion, J. Geophys. Res. (2004), http://dx.doi.org/10.1029/ 2003JD003697.

[7] M.L. Ostraat, J.W. Thornburg O.G.J. Malloy, Measurement strategies of airborne nanomaterials, Environ. Eng. Sci. 30 (2013) 126-132.

[8] A. Lecloux, B., Gorbunov, D., Brouwer, R. Muir, Exposure of workers to carbon nanotubes in a commercial production facility: prelimenary results in the frame of risk assessement and risk management, in: U. Vogel, K., Savolainen, Q., Wu, M. van Tongeren, D., Brouwer, M. Berges (Eds) Handbook of Nanosafety. Measuremment, Exposure and Toxicology, first ed., National Research Centre for the Working Environment, Copenhagen, 2014, pp. 343-360 (version on line 10.01.2014, http://www.eu-vri.eu/filehandler.ashx?file=12399)

[9] B. Gorbunov, R. Muir, P. Jackson, N.D. Priest, Evaluation of the Airborne Particles Fraction Responsible for Adverse Helth Effect, Aerosol Air Qual. Res. (2015), http://dx.doi.org/10.4209/aagr.2013.02.0039, 2013.

[10] Office of Aviation Research Washington, Health Hazards of Combustion Products From Aircraft Composite Materials, Springfield, USA, 1998.

[11] International Organization for Standardization, ISO/TS 27,687:2008 Nanotechnologies. Terminology and definitions for nano-objects. Nanoparticles, nanofibre and nanoplates, 2008.

[12] International Organization for Standardization, ISO/TS 12,805:2011 Nanotechnologies. Materials specifications. Guiadiance of specifying nano-objects, 2011.

[13] M.R. Nyden, R.H., Harris, Y.S., Kim, R.D., Davids, N.D., Marsh, M. Zammarano, Characterizing particle emission from burning composites, Nanotech 2009, Huston, 2009.

[14] C. Motzkus, C. Chivas-Joly, E. Guillaume, S. Ducourtieux, L. Saragoza, D Lesenchal, T. Mace, Characterization of aerosols emitted by the combustion of nanocomposites, in: Conference NanoSafe 2010, Grenoble, 2010.

[15] C. Chivas-Joly, L. Saragoza, C. Motzkus, Evaluation of gaseous effluents and aerosols emitted during combustion of nanocomposites, Mod. Polym. Mater. Environ. Appl. 5 (2013) 67-78.

[16] D. Fleury, B. R'Mili, A., Janes, A., Vignes, J.A.S., Bomfim, S., Sinesi, J.X. Bouillard, New Evidence Towards the Release of Airborne Carbon Nanotubes when Burning Nanocomposite Polymers, Nanotech 2011, ISBN 978-1-4398-7142-3, Vol. 1, 2011.

[17] International Organization for Standardization, ISO 29,904:2013(F) Fire Chemistry - Generation and measurement of aerosols.

[18] M.L. Ostraat, J.W. Thornburg, Q.G.J. Malloy, Measurement strategies of airborne nanomaterials, Environ. Eng. Sci. 30 (3) (2013) 126-132.

[19] Federal Aviation Administration, AC 20-135: Powerplant Installation and Propulsion System Component Fire Protection Test Methods, Standards and Criteria, 2/6/90.

[20] Full-Scale Test Evaluation of Aircraft Fuel Fire Burnthrough Resistance Improvements Office of Aviation Research Washington, D.C. 20,591, DOT/FAA/AR-98/52, Springfield, 1999. 
[21] Federal Aviation Regulations, FAR 25-856-1 Appendix F, part VII Airworthiness Standards: Transport Category Airplanes, Thermal/Acoustic Insulation Materials, Test Method to Determine the Burnthrough Resistance of Thermal/Acoustic Insulation Materials.

[22] Q. Wu, W. Zhu, C. Zhang, Z. Liang, B. Wang, Study of fire retardant behavior of carbon nanotube membranes and carbon nanofiber paper in carbon fiber reinforced epoxy composites, Carbon 48 (2010) 1799-1806.

[23] T. Kashiwagi, E. Grulke, J. Hilding, R. Harris, W. Awad, J. Douglas, Thermal degradation and flammability properties of poly(propylene)/carbon nanotube composites, Macromol. Rapid Commun. 23 (2002) 761-765.

[24] T. Kashiwagi, F.M. Du, J.F. Douglas, K.I. Winey, R.H. Harris, J.R. Shields, Nanoparticle networks reduce the flammability of polymer nanocomposites, Nat. Mate.r 4 (2005) 928-933.

[25] T. Kashiwagi, E. Grulke, J. Hilding, K. Groth, R. Harris, K. Butler, J. Shields, S. Kharchenko, J. Douglas, Thermal and flammability properties of polypropylene/carbon nanotube nanocomposites, Polymer 45 (2004) 4227-4239.
[26] S. Peeterbroeck, F. Laoutid, JMT, F.M. aulemesse, J.M.L. onteverde, J.N. opez-Cuesta, M.A. agy, P.D. lexandre, ubois, Polymer coated corbon nanotube composites, Adv. Funct. Mater. 17 (2007) 2787-2791, http://dx.doi.org/10. 1002/adfm.200600936.

[27] B. Schartel, P. Pötschke, U. Knoll, M. Abdel-Goad, Fire behaviour of polyamide 6/multiwall carbon nanotubes composites, Eur. Poylm. J. 41 (2005) 1061-1070.

[28] S.S. Rahatekar, M. Zammarano, S. Matko, K.K. Koziol, A.H. Windle, M. Nyden, T. Kashiwagi, J.W. Gilman, Effect of carbon nanotubes and montmorillonite on the flammability of epoxy nanocomposites, Pol. Deg. Stab. 95 (2010) 870-879.

[29] S. Peeterbroeck, F. Laoutid, J.-M. Taulemesse, F. Monteverde, J.-M. Lopez-Cuesta, J.B. Nagy, M. Alexandre, P. Dubois, Mechanical properties and flame-retardant behavior of ethylene vinyl acetate/high-density polyethylene coated carbon nanotube nanocomposites, Adv. Funct. Mater. 17 (2007) 2787-2791. 